\title{
ESCUELA Y BARRIO: MEMORIAS Y NARRACIONES DE LA DEMOCRACIA Y LA DICTADURA ARGENTINA
}

\author{
María Alejandra Corbalán ${ }^{*}$
}

\begin{abstract}
RESÚMEN: A través de la memorización y la narración de miembros de un gabinete psicopedagógico del Sistema Educativo de la Provincia de Buenos, se recorre la trayectoria de un barrio y de una escuela, a la par que se recrea la historia de Argentina desde la década de 1970. Dos categorías importantes van norteando el análisis: dictadura y democracia.
\end{abstract}

Palabras claves: Memoria. Dictadura. Democracia. Escuela. Educación.

\section{SCHOOL AND NEIGHBORHOOD: MEMORIES AND NARRATIVES of THE ARGENTINE DEMOCRACY AND DICTATORSHIP}

\begin{abstract}
The history of a school and a neighborhood is retraced through memories and narrations of a Psycho-pedagogic cabinet of the educational system of the Buenos Aires Province. At the same time, the Argentine history from the 1970s onwards is recreated. The analysis is mainly structured around two categories: dictatorship and democracy.

Key words: Memory. Dictatorial regime. Democracy. School. Education.
\end{abstract}

Doctora en Educación y investigadora del Núcleo de Estudios Educativos y Sociales (NEES), Facultad de Ciencias Humanas de la Universidad Nacional del Centro de la Provincia de Buenos Aires (UNCPBA), Argentina. E-mail: Acorba2002@yahoo.com.ar 


\section{Introducción}

$\mathcal{L}$

a escuela por el mero hecho de ser una institución desempeña una función instituyente, gozando de la capacidad de instituir reglas de juego bajo las cuales se dirimen las relaciones sociales, a la vez que se crean y recrean dispositivos orientados a los procesos de enseñanza aprendizaje.

Si bien gran parte de estos objetivos han sido universales, es posible advertir la configuración de prácticas y culturas particulares y específicas, producto de la heterogeneidad de públicos y sectores sociales a los que escuela atiende. Las políticas educativas, de manera explícita o bien velada, han venido contemplando estas diferencias, sin embargo poco han logrado para atemperarlas y acortar las brechas entre un sector social y otro. A través de la escolarización la escuela va concretando, sobre una polimorfa propuesta una preparación "para", sin que este "para" sea claramente definido o definitivo.

En este artículo, a través de entrevistas, concedidas por miembros de los gabinetes psicológicos o pedagógicos de escuelas primarias de la Provincia de Buenos Aires de Argentina, ${ }^{1}$ hemos intentado trazar un recorrido de la educación, la escuela y la escolarización desde mediados de la década de 1970 hasta los finales de 1990. Con estos relatos intentamos aproximarnos a las transformaciones sufridas en un mismo espacio barrial y escolar, el cual puede ser considerado como un exponente en pequeña escala de lo sucedido a nivel nacional, al menos para poblaciones afectadas por situaciones similares.

El barrio conocido como Villa Diamante - como el conjunto de la sociedad argentina -, donde nuestras entrevistadas ejercieron su labor, sufrió importantes transformaciones en estas décadas. En los inicios de 1970 era un barrio obrero de inmigración europea, cuyos pobladores trabajaban mayoritariamente en la construcción y en curtiembres localizadas en el mismo. Más tarde se fueron agregando asentamientos precarios, conocidos en Argentina como "villas miserias". Por ende, "el para qué" de la escuela será considerado en relación con un sector poblacional, compuesto por familias obreras con estabilidad laboral aunque con deficiencias en su calidad de vida, situación que se agravó cuando éstos pasaron a convertirse en desempleados casi permanentes y mal o bien asistidos por el Estado, o en trabajadores precarizados e informales. 
Augé (1996) propone aprehender en un mismo contexto no sólo lo que perdura, sino aquello que lo transforma en profundidad, lo que significará para nosotros estudiar la diferencia en el espacio, en este caso en el barrio y en la escuela, como un camino para entender parte de los problemas de un contexto histórico social durante un período de profundas transformaciones sociales, políticas, económicas y culturales.

Más allá de las transformaciones acaecidas en Argentina, interesa resaltar que la década del setenta se vio atravesada por dos dictaduras (1966-1973) y (1976-1983), la última se vinculó especialmente con el inicio del modelo neoliberal por vía del ejercicio de un terrorismo de Estado, altamente represor y violento. Con el advenimiento de la democracia, si bien se restablecieron las prácticas democráticas formales y la represión por esta vía desapareció, los procesos de precarización se acentuaron tanto como la inequidad.

Dado que el período analizado transitó entre dos formas de gobierno, una de nuestras intenciones fue considerar las posibles diferencias durante la democracia y la dictadura al interior de la escuela y en el entorno barrial/comunitario donde ésta se localizaba.

La historia argentina del siglo XX sufrió una permanente alternancia entre gobiernos democráticos y dictatoriales. Entendiendo por gobiernos democráticos aquellos en los se ejercen los derechos ciudadanos y no existen restricciones para acciones de naturaleza expresiva, comunicativa, organizativa al menos en términos formales, mas allá de que muchos derechos puedan estar condicionados o restringidos para amplios sectores sociales por una desigual distribución de los bienes y servicios, atribuibles a políticas inequitativas, al tipo de proyecto político y a los sectores socio-económicos que hegemonizan el poder del Estado. En el caso de las dictaduras, lo que queda anulado es el formal ejercicio del derecho ciudadano en la elección de sus autoridades y en el gobierno de las distintas instituciones representativas, con la consecuente supresión de los órganos formales de una democracia liberal. A lo que se agrega, en el caso de la última dictadura argentina, un aparato represivo y de control por parte de las Fuerzas Armadas, quienes asumen el gobierno del Estado, generando lo que se conoce como terrorismo de Estado, en la medida que todo habitante queda sujeto al libre arbitrio de su voluntad y de sus acciones. La supresión de las libertades y derechos ciudadanos y un aparato de control y represión se convirtieron en los mecanismos para 
la implementación de las políticas neoliberales que luego se profundizarán en la democracia.

La dictadura, sobre todo la acaecida entre 1976-1983, ha tenido y tiene una presencia permanente. ${ }^{2}$ Pues aunque finalizó en 1983 dejo importantes y dolorosas secuelas, ${ }^{3}$ que fueron emergiendo en los años sucesivos dotando de gran visibilidad a los hechos que durante la misma acontecieron. Por diversos motivos, durante la más extensa democracia vivida en Argentina desde 1983, la sociedad ha creado una estructura de funcionamiento socio-cultural basada en la recuperación de la memoria, en la lucha contra la impunidad y por la justicia. La recuperación de la memoria y distintas formas organizativas no han quedado sólo restringidas a los hechos represivos y violentos de la dictadura, otros hechos acaecidos en democracia convocan a un ejercicio similar de prácticas y reclamos. La conjunción entre memoria, organización y reinvidicacion es un proceso permanente, activado bajo acciones recordatorias y reparadoras, ejercida por distintas vías, rituales y actores. ${ }^{4}$ Es quizás, por esta particularidad, que, como analistas sociales, nos vemos convocados e interpelados a reflexionar las cuestiones socioeducativas desde estas amplias y complejas categorías. Por un lado la que se refiere a las formas de gobierno y por otro la presencia de la memoria como un recurso permanente que forma parte de la cultura casi cotidiana de una parcela importante de la sociedad argentina.

\section{Dictadura y...}

Cuando las entrevistadas relatan sus recuerdos, rememoran una serie de disposiciones disciplinarias del período dictatorial que operaban sobre las formas en las que el cuerpo era vestido, arropado, cubierto, así como también sobre la forma en que debía ser cuidado el cabello y el tipo de calzado: "prohibición del uso del pantalón en las mujeres y de las zapatillas para todos, cabello corto para los varones, rostro despejado y visible para las mujeres".

Estas exigencias y formalismos, que inhibían la particularidad de expresión de cada sujeto, uniformizando las presencias, fueron consecuencia de un desplazamiento y de una gran impregnan cía en la vida cotidiana de procesos provenientes del ámbito militar hacia el escolar y social en general, con ciertas connotaciones específicas en el caso de 
la escuela, que afectaban tanto al personal directivo y docente como a los alumnos. La rigidez y autoritarismo en el trato de la directora hacia alumnos y docentes había contaminado el lenguaje pues ésta era tildada de "milica" por nuestras entrevistadas, expresión que provenía del campo militar.

Pero si bien las entrevistadas advierten cambios y reconocen hitos durante estos 30 años de historia argentina, estos no son registrados bajo la lógica de la dicotomía dictadura-democracia. Parecería que la escuela hubiese desenvuelto una lógica endógena que no advertía diferencias entre el clima dictatorial o democrático que impregnaba el entorno. Gran parte de esta "sensación" puede atribuirse al carácter regulador per-se que tiene la escuela y con ello a la existencia de un cierto habitus que permanece: "En la escuela pasan los gobiernos y no hay grandes cambios".

A pesar de las cuestiones mencionadas, observamos que en las modalidades de enseñanza y aprendizaje hubo cambios a partir del advenimiento de la democracia.

De un trabajo más unilateral y verticalista en la relación docentealumno durante la dictadura, se fue gestando, convalidando y promoviendo con el advenimiento de la democracia - por parte de los órganos de gobierno del sistema educativo nacional y provincial - una relación más dialógica y horizontal tendiente a incrementar los niveles de participación y a reactivar prácticas más democráticas: "A la directora no le gustaba que hablara, sino que trabajara, hiciera..." (recuerdos correspondientes al período dictatorial).

El recelo respecto a la reunión, a lo grupal, a lo comunicativo sucedía no sólo en la escuela sino también en los otros entornos del medio argentino, pues estaban prohibidas las reuniones gremiales, políticas y aún las culturales y recreativas eran controladas y miradas con desconfianza. Aunque, otras movilizaciones grupales y colectivas fueron funcionales y los militares las utilizaron para exaltar valores nacionalistas que enmascaraban y ocultaban los procesos altamente represivos que sufría, simultáneamente, una importante parte de la sociedad argentina. Ejemplo de ello fueron las prácticas ejercidas durante el mundial de football de 1978 que se realizó en este país, y más tarde, en 1982, con la guerra contra Inglaterra por la recuperación fallida de las Islas Malvinas. De allí que pueda inferirse que la sociabilidad pudo verse interferida diferencialmente en uno y otro régimen de gobierno. 
Escuela y barrio: memorias y narraciones de la democracia y la dictadura argentina

\section{Escuela-barrio y sociabilidad}

Si bien en cualquiera escuela se concreta una sociabilidad formal que se identifica con la institucional - la que por lo general ha tendido a un proceso de homogeneización canalizado y reforzado por la política educativa nacional y-/o provincial de turno -, se advierte una importante heterogeneidad entre las escuelas del sistema educativo provincial, hecho que se ha supeditado - a veces fuerte y otras débilmente - al tipo de comunidad y contexto en el que cada escuela está enclavada. Lo que permitiría hablar de una segmentación dentro del mismo y de una heterogeneidad y multiplicidad en las trayectorias educativas.

La sociabilidad en la década de los 70 , en el barrio analizado, se articulaba sobre una base comunal. La comunidad tenía todavía un sentido de lugar que les daba identidad y pertenencia a sus miembros, por un lado porque la mayor parte de los varones del barrio trabajaban en las curtiembres lo que los tornaba compañeros de trabajo, pero también por la presencia de familiares y amigos próximos. La familia y la tradición comunal jugaban un papel primordial que se fue alterando en los finales de esta década. A la sociabilidad institucional semiurbana se le fue agregando una sociabilidad más urbana. Estos últimos elementos se fueron concretando de manera irregular y desordenada, alterando el espacio de sociabilidad comunal. Hasta entonces, era frecuente la existencia de grupos informales gestados en su mayoría a partir de lazos familiares ampliados y vecinales. Pero, con el correr del tiempo, a lo urbano se añadió en estos territorios, un fenómeno ya existente en otros barrios y lugares del conurbano bonaerense: la aparición de nuevos asentamientos poblacionales precarios. Estos fueron producto de distintos factores, pero el más relevante fue la migración forzada desde la ciudad de Buenos Aires hacia el conurbano de la provincia, por la erradicación de las villas de emergencia. La política del gobierno de la ciudad, en un intento "modernizador", construyó autopistas pero también erradicó los asentamientos denominados villas miserias o de emergencia, configuradas por población proveniente de países vecinos, especialmente bolivianos y paraguayos y de otras provincias argentinas.

También cabe mencionar que en 1981 se inicia un nuevo estilo de poblamiento, aunque no registrado en el barrio analizado, pero que por su cercanía tuvo influencia un tiempo más tarde. Este se correspondió con asentamientos con otros niveles de organización e intentos 
urbanísticos diferentes a las villas de emergencia, pues promovieron el trazado de calles, un espacio delimitado y equitativo por familia y el diseño de áreas de servicios comunes (salita de salud, escuela, etc.), intentando crear una nueva espacialidad y territorialidad que más se asemejara a los barrios obreros pre-existentes que a las villas. Estos movimientos, a pesar de haber sido incipientes durante la dictadura, se iniciaron con ella; contaban con el apoyo de las Comunidades Eclesiales de Base provenientes de ciertos sectores progresistas de la Iglesia Católica y con el apoyo de los curas del Tercer Mundo influidos por ciertas experiencias iniciadas en el Brasil, que evitaron, en algunos casos, la erradicación y dieron posibilidad a la ampliación y consolidación de dicho movimiento en el conurbano bonaerense (Maiorana, 2008).

La villa era más comunidad... humildes, pero había un tejido social más sólido. Había referentes sociales, podían ser personas grandes, habitantes más antiguos, más sedentarios, pero esto se fue perdiendo desde la cultura de la alimentación (...) había santiagueñas que trasmitían la cultura de la comida santiagueña, eran maestros de otros (...) quien sabia hacer trabajos manuales también era valorado, pero cuando en el 90 llegaba todo por 2 pesos se rompen estos vínculos.

A la vez, otro fenómeno contribuyó a transformar la sociabilidad familiar tanto como la de amigos y vecinos. Con la hiperinflación acaecida en 1989 - surgieron las ollas populares, los comedores escolares y otros emprendimientos similares organizados por distintos movimientos sociales, ciertas iglesias, a fin de asistir alimentariamente a un número importante de la población. La satisfacción de esta carencia instituye estos lugares, que si bien preservan el carácter grupal, no son elegidos, ni fácilmente tolerados desde la autoestima, el estigma y autoestigma, que se configura sobre los sujetos que hacen uso de estos servicios. En realidad se erigen y son adoptados como una de las tantas estrategias de sobrevivencia, además de que posteriormente hayan servido de disparador para importantes y duraderas organizaciones sociales de signo variado.

Nuestras entrevistadas, todas ellas miembros del Gabinete Psicopedagógico, conformado por una maestra recuperadora, una Asistente Educacional y una Asistente Social se desempeñaron durante tres décadas en las escuelas de este barrio. ${ }^{6}$ Ellas ingresan a trabajar en 1976 en una de las escuelas del barrio, año en el que en Argentina se produce el 
Escuela y barrio: memorias y narraciones de la democracia y la dictadura argentina

Golpe Militar del 24 de marzo. Su formación la habían realizado durante la dictadura anterior. Fueron varios los encuentros con nuestras entrevistadas, en las que se les invitaba a relatar sus recuerdos pues en el presente ya todas ellas están jubiladas. De modo que el relato fue evocativo y apelando a su memoria, también ayudaron a esta reconstrucción diversos materiales que aún preservaban (planificaciones, normativas, instructivos oficiales, materiales didácticos, informes, etc.).

El Municipio de Lanús Oeste, donde se localizaba este barrio limita con la ciudad de Buenos Aires, y lo separa un riachuelo y a la vez lo comunican dos puentes. Su creación oficial data del año 1945, en la que ya poseía cierta fisonomía adquirida con la creación de una estación de ferrocarril en los inicios del siglo XX, ramal que se dirigía hacia el sur del país. Desde el siglo XIX existían, en este lugar, los saladeros, que más tarde darán origen a las curtiembres, estas últimas nacieron en consonancia con los procesos de sustitución de importaciones, desde finales de la década de 1930, las cuales ayudaron a la conformación de este barrio obrero. La localidad de Lanús esta integrada por otras cinco entidades, las cuales presentan configuraciones diversas en términos de su fisonomía más o menos urbanas, destacándose zonas fabriles, comerciales y habitacionales. La heterogeneidad también obedece a la composición socioeconómica de sus habitantes. Lanús Oeste tenía, según el censo del 2001, una población de 156.953 habitantes.

Esta escuela funcionaba en un gran galpón de chapa, ${ }^{7}$ el cual albergaba, en precarias subdivisiones, a las diferentes aulas y otras dependencias escolares. Las aulas no tenían ventilación y su iluminación provenía de aberturas hechas en el techo y cubiertas por un poliuretano transparente. Para una matrícula que oscilaba entre 700 y 1.000 alumnos, que se distribuían en dos turnos de 4 horas cada uno, sólo existían dos excusados sin cloacas. ${ }^{8}$ Sus alumnos eran del barrio y provenían en su mayoría de los asentamientos precarios, donde las familias - en general numerosas - se hacinaban en una única habitación.

En este contexto los niños asistían a la escuela, a su escuela, y "ella se tornaba en un lugar importante... La escuela era la única posibilidad de salir de su casa y encontrarse con otros. Yo allí era la señorita maestra (...). Los chicos llegaban con ganas de jugar, de aprender...”.

La función de la maestra recuperadora se centraba en asistir a los alumnos que presentaban dificultades en su aprendizaje escolar; en 
la mayor parte de los casos éstas eran consecuencia de las condiciones sociales en la que el alumno desarrollaba su experiencia de vida. De allí, que una maestra recuperadora era alguien muy próximo a aquellos alumnos que durante el tránsito por la escuela sufrían escollos, impedimentos y dificultades. En esta función y en esta relación, se jugaba un fuerte reto para el docente, quien con su accionar comprometía su propia trayectoria profesional; mas también el reto era para el alumno. Aunque no siempre explicitado, había un desafío compartido que los tornaba interdependientes. Gestaban un vínculo particular, que, en el caso del docente, lo orientaba a una incesante búsqueda pedagógica-metodológica para hacerlos salir de ese lugar de "distinción" en el que quedaban situados cuando recibían asistencia de una maestra recuperadora. Que un alumno estuviera en condiciones de retornar e integrarse al grado común era parte de la meta y de la interdependencia. Por las condiciones de precariedad escolar, los docentes contribuían con su propio esfuerzo y recursos materiales a los vacios que dejaba el sistema educativo. La mayor parte de éstos eran provistos por el personal docente (libros, juegos, láminas, papelería, etc.). Sin embargo, este vínculo afectivo y "asistencialista" no obturaba los aspectos pedagógicos y contribuía para que el rol docente no se ejerciera de manera burocrática.

A ello también contribuía el perfil del directivo y de la inspectora: "La inspectora era muy severa, quería que trabajáramos... y no habláramos. Era muy milica. Quizás gracias a este tipo de personalidad nacieran proyectos de tipo pedagógico y de otra naturaleza dentro de la escuela”.

Uno de ellos producto de la precariedad edilicia de la propia escuela. Mejorar el hábitat escolar, tornarlo más habitable, organizar espacios que se parecieran más ámbitos escolares prototípicos fueron una iniciativa de los miembros de esta escuela. Es en este contexto que se elabora un documento sobre la memoria, el espacio, la organización espacial, que facilita una suerte de capacitación in situ.

En ese entonces la escuela no brindaba almuerzo, sólo una taza de leche con pan, financiada por el Estado provincial. Existía un ropero escolar producto de lo que los miembros de la comunidad escolar conseguían. La última dictadura desactivó también un consultorio odontológico remante de otras épocas educativas. Además existían nexos con otras instituciones del barrio y con figuras referenciales, como la monja 
Escuela y barrio: memorias y narraciones de la democracia y la dictadura argentina

que daba apoyo escolar, o bien "Un médico del barrio, que trabajaba en un hospital público, y en las tardes atendía en su consultorio de forma gratuita, muchas veces con la ayuda de colegas del hospital”.

Mientras continuaba la dictadura se construía un nuevo edificio para esta escuela, que había nacido como una escuela conocida como Lainez. La ley Lainez fue promulgada en 1905 e impulsó la creación de escuelas en el ámbito nacional, sobretodo donde el analfabetismo fuera relevante, situación que se agudizaba especialmente en las zonas rurales y carenciadas. Estas nacían como parte de la solicitud de la propia comunidad, y su edificio en general era cedido también por miembros de la misma. Ello explicaría las características edilicias de esta escuela.

Para algunos historiadores de la educación, esta Ley habilitó un doble sistema educativo, que funcionaba en paralelo con aquel creado mediante la Ley 1420. Esta última, sancionada en 1884, instituyó la educación laica, gratuita y obligatoria, la cual, relativamente incumplida en ciertas provincias y regiones en los albores del siglo $\mathrm{XX}$, hicieron que surgiera en el diputado Laínez tal preocupación y que diera origen a la ley que lleva su nombre.

Hasta la década de 1930 estas escuelas, bajo la jurisdicción del Consejo Nacional de Educación ( $\mathrm{CNE}$ ), sólo cubrían una escolaridad de cuatro años, y no de seis como las escuelas provinciales; en general estaban a cargo de un docente único y la formación de los mismos era ejercida en ámbitos diferentes a las Escuelas Normales, donde se concretaba la mayor parte de la formación docente. Mas, a partir de 1950, el CNE faculta a las provincias para que estas escuelas sean transferidas a su órbita, proceso que termina de concretarse en 1978 (Ministerio de Educación, Ciencia y Tecnología, 2005).

Barrio y escuela. Disputando espacios...

Durante el proceso de construcción del nuevo edificio, el personal escolar fue elaborando algunos proyectos, uno de ellos ligado al posible destino del galpón que quedaría en desuso. Se pensó en un centro de recreación que funcionara en contra turno escolar y durante los fines de semana. El carácter lúdico que se fue imprimiendo a la función "recuperadora" animó a los demás docentes a promover la creación de 
este centro. Sin embargo, "Cada vieja aula fue ocupada por una familia que nunca era menor a los cinco miembros".

Hasta mediados de la década de 1980, la mayoría de los padres varones del barrio tenía trabajo, pero con la desaceleración del proceso industrializador como parte del programa neoliberal iniciado con la dictadura, las curtiembres reducen su personal o bien se cierran. Así se inicia el desempleo. Esto último también producto de la desaceleración de la construcción, tarea en la cual trabajaba una parte importante de los padres.

La nueva escuela habilitada en la democracia (1984) perdió su patio, pues este, así como el viejo galpón, había sido ocupado por distintas familias para armar sus precarias viviendas. La problemática de la vivienda se fue agudizando en el barrio conforme se expandía el desempleo, a la par que se activaban procesos más democráticos en el ámbito escolar, y políticas sociales que intentaban paliar los efectos de la hiperinflación y el desempleo.

El abandono del patio por parte de las familias se dio en parte gracias a las incipientes iniciativas ligadas al hábitat y la vivienda, nacidas de aquellas primeras ocupaciones en barrios próximos. Así a la par que el patio retornaba para el uso escolar, también se pudo lograr que la escuela se expandiera.

La escuela nueva era de dos pisos muy bonita. También la escuela tuvo dos salas para Jardín de Infantes que antes no había, varios baños, comedor, cocina y la matricula creció a 1200 alumnos. En el turno de la noche se hizo una escuela primaria de adultos. En los dos turnos escolares los alumnos recibían su copa de leche y almuerzo que también incluía a los niños de Jardín de Infantes. En la dictadura la escuela no alimentaba, conseguíamos a través de donaciones y muchas veces éramos los maestros quienes llevábamos algo... apenas existía el llamado "ropero" provisto por los propios docentes, como también las estufas con las que se calentaban las aulas durante el invierno. Durante un tiempo Caritas, en el turno de la tarde, daba leche.

\section{Docentes y directivos: pertenencias y afinidades}

En 1976 existían en la provincia de Buenos Aires tres tipos de escuelas primarias: las privadas, las provinciales y las escuelas Lainez. 
Escuela y barrio: memorias y narraciones de la democracia y la dictadura argentina

La mayor parte de los docentes y directivos de estas últimas provenían de las provincias argentinas, como también lo eran muchos de sus alumnos. Era notoria la presencia de esposas de militares entre las docentes, explicada, en parte, por su pertenencia a las escuelas Lainez, que permitían a las esposas de militares solicitar una nueva plaza cuando sus maridos eran trasladados. Por su adscripción a estas escuelas ellas debían trabajar en escuelas provinciales, de allí que este barrio fuese evaluado favorablemente por la proximidad a la ciudad de Buenos Aires, donde en general residían. La población docente también se conformaba por personal que iniciaba su carrera profesional, como es el caso de nuestras entrevistadas. Carrera que en general comenzaba en escuelas más desfavorecidas. Por tanto, en un caso como en otro, los márgenes de elección eran limitados y quedaban condicionados por uno u otro motivo. Las características de la escuela generaban ciertas reticencias para ser elegida como lugar de trabajo.

En las ex maestras Lainez se percibía una cierta diferencia con respecto a los otros docentes, denotada en su vestimenta, en sus coches. Sin embargo establecían con los alumnos, los vecinos de la escuela y los padres una relación bastante fluida, producto en parte de una empatía que nacía por tener una misma pertenencia provincial que los identificaba y les permitía disponer de códigos comunes, diferente a lo que sucedía con aquel personal más joven, familiarizado o perteneciente a la ciudad de Buenos Aires y con escasos vínculos con las provincias del interior del país. Las primeras "Se comprometían mucho con los pibes, había afecto y profesionalismo... Creo que ahí se sentían importantes, se sentían más seguras que en Buenos Aires por ser gente del interior”.

También había docentes más antiguas donde el vínculo con el entorno comunitario de la escuela y con el alumno difería en relación a las más jóvenes: "las más viejas entendían mejor a los chicos, las más jóvenes no tanto...".

El tiempo de permanencia en estas escuelas había ayudado a crear en las maestras más antiguas una importante familiaridad con las condiciones de vida de sus alumnos, con sus carencias, el hacinamiento en que vivían; tenían una más fácil comprensión de los efectos que estas situaciones provocaban y que tantas veces se ponían de manifiesto en la escuela: sueño, cansancio, dificultades para concretar tareas escolares, frío, hambre, apatía, desatención. 


\section{Democracia y...}

Con el retorno de la democracia se instalan ciertas políticas sociales, algunas de las cuales se concretan teniendo como epicentro a la escuela. Una de éstas dirigida a la asistencia alimentaria, mediante las llamadas Cajas Pan, convertiendo a la escuela en un lugar de almacenamiento y distribución y a la vez de clasificación y control. Tanto es así que una de las aulas, la destinada al trabajo de la maestra recuperadora, fue convertida en lugar de acopio de las Cajas. También fue tarea del asistente social confeccionar la lista de los alumnos que comerían: "Era una tarea a la que me resistía, con que criterio seleccionaba a unos sí y a otros no?".

Pese a la precariedad socioeconómica de los habitantes del barrio, la deserción escolar no era tan acentuada, como pasó a serlo en años posteriores cuando la crisis social se agravó con la profundización del modelo neoliberal, durante el menemismo: "En ese entonces había 40 chicos en primer grado, en 1998 había 18”.

La droga no era todavía un problema pero si el desempleo paterno, que comenzó a agravarse y con ello sobrevino un cambio importante al interior del núcleo familiar y en la propia escuela: "El padre desocupado en su casa, abatido, agresivo, alcohólico, indiferente, impotente".

La madre se torno en la proveedora, a veces prostituyéndose, o bien realizando trabajos sin estabilidad, ni seguridad social y con bajos salarios. Los hijos más desprotegidos, más abandonados a su suerte. Conforme se acentuaba la crisis, que hizo eclosión en el 2001, "el refugio no fue necesariamente la escuela sino el alcohol, la droga y actos delictivos".

\section{Un disciplinamiento sin dictadura}

En Argentina el retorno a la democracia no generó cambios respecto al programa socioeconómico de corte neoliberal. Este se continuó aún durante la débil democracia inicial, jaqueada por el poder de los militares, una alta deuda externa, ${ }^{9}$ una desocupación instalada en amplios sectores de la población y en el barrio de esta escuela. Sin embargo, el modelo neoliberal entró de lleno con las Reformas Estructurales que propicio Carlos Menen durante sus dos gobiernos (1989-1993 y 1993- 
Escuela y barrio: memorias y narraciones de la democracia y la dictadura argentina

1998) y que continuaron y eclosionaron en la crisis del 2001 durante el gobierno de De La Rua.

En lo que hace a las políticas educativas nacionales, en los comienzos de las Reformas se privilegiaron acciones orientadas a un público, especialmente aquel que tenía afinidad con respecto a la población "privilegiada" del primer mundo, oficialmente se configuró un discurso que fue sustituyendo la idea de igualdad por el de equidad, el de políticas universales por focalizadas, incrementando las categorías clasificatorias de la población en general. De hecho y por efecto de la ampliación de las comunicaciones, los sectores privilegiados, el de los negocios y aún el del campo académico de cualquier país, fueron configurando una suerte de campo común, en el cual se advierten semejanzas en sus prácticas y gustos que facilita sus conexiones e intercambios.

Junto con estos procesos se inician aceleradamente los procesos de privatización de bienes y servicios estatales, y el discurso oficial - re trasmitido y ampliado por los medios de comunicación - proclamaba las bondades de las reformas estructurales como un camino que conduciría a Argentina a ser una Nación del primer mundo. De hecho ello sucedió, pero sólo para una pequeña minoría que se vio favorecida a partir de una serie de nuevos emprendimientos más orientados hacia el área de servicios y la especulación financiera.

La privatización de la educación como slogan y proyecto fue quizás una de las pocas medidas fuertemente resistidas, aún así la educación pública - tanto la superior como la de los restantes niveles del sistema - sufrió un des-financiamiento a veces embozado y otras veces de manera directa. Mermó o bien se suprimió la ayuda alimentaria, a la salud y otras medidas iniciadas durante el gobierno de Alfonsín (198389), destinadas a la población carenciada.

Las Reformas Estructurales aplicadas a manera de shock, a partir de 1990 y con alta intervención de los Organismos Internacionales de Crédito, conmocionaron la estructura socioeconómica, provocando, entre otras cuestiones, que los sectores carenciados así como también amplios sectores de las clases medias quedaran librados a su suerte.

En este contexto se iniciaron los cambios en el sector educativo, aunque muchas de las acciones programadas abortaron antes de iniciarse y otras se fueron implementando con muchas resistencias y dificultades, agravando, al interior del sistema educativo, las problemáticas no sólo 
pedagógicas sino también las sociales. Los efectos de las reformas estructurales se hicieron sentir con virulencia, afectando a poblaciones cada vez más numerosas. La pobreza, la desocupación y otras manifestaciones asociadas, como el deterioro de la salud, la alimentación, la precariedad habitacional, por mencionar sólo algunas, fueron parte de las problemáticas. Este conglomerado de sujetos afectados por las reformas estructurales no pudo ocultarse ni eliminarse. Debió ser mediano o mínimamente asistido. Nacen allí las políticas focalizadas, y una asignación de roles socio asistenciales, ya no implícitos, para las propias comunidades educativas. Roles que ya se venían desempeñando en ciertas regiones, barrios y escuelas, como la que estamos analizando.

Una de las políticas focalizadas se orientó hacia la infancia y la juventud de los sectores pobres, pero debió hacerse extensiva a amplios sectores de la clase media que pasaron a conformarse en los "nuevos pobres”. Pero aún así continuaron siendo focalizadas, segmentando arbitrariamente a los afectados por las reformas.

En lo que hace a las reformas educativas estas fueron diversas. Una de ellas modificó la estructura organizativa del sistema escolar. Así de una escuela primaria de siete años y una media de cinco, se pasó a una Educación General Básica (EGB), organizada en tres ciclos de tres años y un polimodal de tres años, entre otros motivos producto de la ampliación de los años de obligatoriedad escolar, que de siete años se extendió a diez. En paralelo se intensificó el proceso de descentralización - iniciado en la década de 1970 - de los servicios educativos, los cuales cambiaron su pertenencia.

Se estableció que estas reformas podrían ser instrumentadas a criterio de cada provincia. La de Buenos Aires, donde se localizaba esta escuela, inició la reforma y puso en marcha el programa para dar cumplimiento a la ampliación de los años de obligatoriedad y a la instalación de la EGB a partir de un fuerte endeudamiento generado con el Banco Interamericano de Desarrollo (BID) y el Banco Internacional de Reconstrucción y Fomento (BIRF). Pese a ello, cuando el empobrecimiento de las familias se radicalizó, la escuela se convirtió en el espacio de satisfacción de necesidades básicas y las reformas iniciadas se detuvieron o mutaron. ${ }^{10}$

La escuela fue escogida como la institución privilegiada para paliar las secuelas del modelo neoliberal. El gobierno provincial intensificó 
Escuela y barrio: memorias y narraciones de la democracia y la dictadura argentina

algunas políticas orientadas a "retener al alumno en la escuela" (Martignoni, 2008, 2002). Dos razones fundamentales se esgrimían detrás de esta decisión: por un lado el peligro que representa para los niños- la calle y, por otro, el riesgo para los “otros" del niño en la calle. En gran medida tal situación hizo que las exigencias pedagógicas se tornaran más laxas y flexibles. Sobretodo se puso en marcha una serie de normativas más permisivas con respecto a la exigencia de la asistencia al establecimiento, como también se ampliaron las oportunidades de recuperación y apoyo a los alumnos frente a las dificultades de aprendizaje escolar. Todo ello orientado a que el alumno permanezca dentro de la escuela.

Cabe señalar que la provincia de Buenos Aires concentra casi un tercio de la población total del país, aunque ella es heterogénea, pues incluye al amplio conurbano que rodea a la ciudad de Buenos Aires capital del país - y a la zona agrícola ganadera, compuesta de ciudades medianas y pequeñas, que concentran a productores medios y a sectores pertenecientes a la tradicional oligarquía terrateniente, así como también a nuevos grupos de inversionistas nativos y extranjero. En el caso del conurbano, se polarizan los estratos sociales entre los pertenecientes a los sectores más desposeídos que componen sobre todo la zona sur-oeste, donde están situados el municipio de Lanús y otros bolsones en los que se observan altos contrastes de riqueza y pobreza.

\section{Estrategias para el disciplinamiento}

No sólo durante la dictadura, la escuela se dedicó a producir clasificaciones, naturalizaciones y a gestar mecanismos de control y disciplinamiento. Qué observar y qué mirar de un alumno no son prácticas neutras, tienen por detrás un efecto clasificatorio y distintivo. Aunque los procesos de disciplinamiento, durante los períodos dictatoriales tornaban en potencial víctima al conjunto social, produjeron sus propios criterios clasificatorios y selectivos, convirtiendo en más vulnerables a ciertos estratos y grupos. Sobre estos grupos seleccionados el disciplinamiento estuvo fuertemente marcado y visible en los cuerpos, ya sea por su provocada invisibilidad a través de la figura del desaparecido, como por las torturas y encierros en los campos clandestinos de detención, mas también en las exigencias en las vestimentas que ya mencionáramos, y en un conjunto importante de prohibiciones e impedimentos. 
El gabinete del cual dependían nuestras entrevistadas es una dependencia de la Dirección de Psicología y Asistencia Social Escolar perteneciente al sistema educativo provincial. De las instrucciones giradas a estos equipos, a fin de confeccionar los informes sobre los alumnos, se enviaban al personal docente y de gabinete un conjunto de tópicos a partir de los cuales los alumnos eran evaluados y clasificados. ${ }^{11}$ Estas tareas de observación, registro y clasificación eran ejercidas no sólo por el maestro, sino también por algunos de los otros miembros del Gabinete. La asistente social registraba "las necesidades" y tenía por función gestionar "cosas a las familias de los alumnos y también con la idea de formarlos en hábitos de higiene, alimentación”.

Pero los procesos clasificatorios continuaron con la democracia, sobre todo cuando las políticas sociales debieron incrementar procesos asistencialistas, basados en políticas focalizadas. Gran parte de esta tarea era de incumbencia de la trabajadora social. Sin embargo, similares mecanismos de distinción se advertían entre los mismos alumnos: pan verde era llamado quien recibía la asistencia alimentaria en la escuela.

En realidad la dinámica del capitalismo actual, aún en el marco de procesos democráticos, ha incrementado un proceso de segmentación y acentuación de las diferencias sociales. Las antiguas políticas expulsivas de quienes no tenían éxito en la escuela han cedido paso a políticas de retención, inclusión y re-inclusión, sin atemperar tales diferencias. En gran medida porque esto no es responsabilidad exclusiva de la escuela. En los inicios de esta hecatombe, la escuela se tornó más impotente, no sólo porque no les es fácil cumplir satisfactoriamente los objetivos propios de la escolarización, sino porque también es impotente para producir por sí sola los cambios sociales necesarios o deseados. De allí que pese a los procesos de clasificación y a otras prácticas ejercidas en su seno, no resulta claro cuales son los efectos disciplinadores que produce en términos de otras aperturas o alternativas para los alumnos. La mera retención dentro del espacio escolar, junto a la creación de una expectativa dudosa con respecto a la relación educación trabajo, puede contribuir a frustraciones y aún a la propia descalificación y baja valoración de la institución escolar. 
Escuela y barrio: memorias y narraciones de la democracia y la dictadura argentina

\section{Conclusiones}

Las primeras impresiones que dejaron estas narraciones son de una cierta perplejidad, pues uno de los presupuestos implícitos en torno a las dictaduras es que estas dejan marcas imborrables, duraderas y profundas en los colectivos sociales. Con seguridad que lo han producido, pero de diferente manera según de quien se trate.

En este sentido no está demás remarcar que en Argentina una amplia proporción de la población tiene aún a flor de piel las heridas de la dictadura: familiares desaparecidos, ex detenidos, hijos y nietos aún buscados por sus familias de sangre, ante la sustracción de su verdadera identidad y filiación. También, porque las prácticas reparatorias, instaladas desde el advenimiento de la democracia, son permanentes mas allá de las idas y vueltas sufridas. Cabe recordar que, durante el gobierno de Alfonsín, se inician los juicios a los militares por violación a los derechos humanos. Sin embargo sus condenas son suspendidas por los levantamientos militares durante este gobierno. Posteriormente se suman los indultos concedidos por Menen a los pocos militares que continuaron cumpliendo la condena. ${ }^{12}$ Con el gobierno de Kirchner, en el 2004, se dejan sin efecto las leyes - conseguidas bajo presión militar - y se reinician los juicios interrumpidos. Estos procesos vuelven a reactualizar la historia, reavivan los recuerdos tanto de quienes participan como víctimas o testigos en los juicios.

Fue esta impronta permanente la que explica porque el trabajo se vio direccionado a analizar la escuela bajo esta dicotomía dictadura-democracia. Sin embargo, cuando se indaga acerca de las vivencias al interior de la escuela, en uno y otro régimen de gobierno, no se perciben diferencias notorias en las narraciones de las entrevistadas.

Las dictaduras logran generar miedos, particularmente cuando se valen de un terrorismo de Estado como fue el ejercido durante la última dictadura argentina. Expresión utilizada para referirse a las dictaduras latinoamericanas de las décadas de los 1970/1980, que se ejecutaron en consonancia con las políticas de defensa norteamericanas. Sus consecuencias no sólo fueron prácticas ilegales y violatorias de los derechos humanos, sino que también tuvieron importantes efectos en el plano político, social y cultural.

Uno de los sentimientos que prevalece en las dictaduras es el miedo y la desconfianza. Sin embargo, en los relatos de nuestras entrevistadas, 
no aparecieron de manera manifiesta expresiones que denotaran miedo durante el proceso dictatorial. El miedo se puso de manifiesto en un contexto democrático especialmente a partir de las reformas estructurales del Estado. Es el miedo a la inseguridad, expresado por quienes trabajan en escuelas localizadas en barrios precarios. Las poblaciones pobres y empobrecidas, que fueron y son las víctimas de estos procesos, se convierten en villanos y en objeto de miedo.

La apariencia de selectividad con la que las fuerzas armadas y policiales operaron durante la dictadura atemperó los miedos de manera generalizada. En el imaginario construido por los mismos dictadores quedaban a salvo quienes no tuvieran algún tipo de militancia social y política. Esta creencia reforzada por distintos caminos construyó la idea de que sólo eran determinados sujetos los que podían ser objeto de punición y represión, "aquellos que en algo andaban o estaban", frase bajo la cual se amparaban quienes creían estar a salvo del terrorismo de Estado. Esta creencia quedó diluida con la recuperación de la memoria durante la democracia.

En el transcurso de estas últimas décadas, otros procesos disciplinadores sustituyeron a aquellos ejercidos durante la dictadura. A partir de la democracia, y coincidiendo con la profundización del modelo neoliberal, el disciplinamiento fue de carácter masivo, se orientó hacia el consumidor, el ciudadano, el trabajador y el desempleado, como también hacia la propia estructura burocrática del Estado. Estas nuevas estrategias disciplinadoras sustituyeron y consecuentemente instalaron otras prácticas, dispositivos, creencias, hábitos y costumbres que modificaron significativamente la estructura sociocultural argentina.

La dictadura no socavó necesariamente el carácter del conjunto de la población, pero sí logró este cometido durante la democracia a través de sus políticas de ajuste y reformas estructurales.

(...) el carácter es una palabra que abarca más cosas que la más moderna personalidad, un término referido a deseos y sentimientos (...). El carácter se centra en particular en el aspecto duradero, a largo plazo, de nuestra experiencia emocional. El carácter se expresa por la lealtad y el compromiso mutuo... El carácter se relaciona con los rasgos personales que valoramos en nosotros mismos y por los que queremos ser valorados. (Sennett, 2000, p. 10) 
Escuela y barrio: memorias y narraciones de la democracia y la dictadura argentina

El impacto sobre esta esfera del ser humano aconteció de manera generalizada en democracia más allá que las improntas autoritarias se fueran configurando en las distintas dictaduras vividas.

La dictadura se apoyó en el ocultamiento, en lo no dicho, en lo no visto, operó en la clandestinidad, pero también a través de un discurso que dividía, mentía y creaba antagonismos, recelos, desconfianzas y distanciamientos en el colectivo social. Aunque otras veces su visibilidad era ostentosa: en los operativos desembozados contra sus víctimas, en la quema de libros, en la prohibición de ciertos contenidos curriculares, en las normativas sobre la vestimenta, en la prohibición de las actividades gremiales y tantas otras de naturaleza socio comunitaria. Sin embargo esta visibilidad se lograba de manera diferenciada, había un entorno próximo y otro más distante respecto al accionar represivo. El primero de ellos más ligado a las víctimas, a sus familias y amigos, quienes tenían una vivencia próxima y directa. Sin embargo en democracia la visibilidad de los hechos y prácticas de la dictadura no han quedado restringidas a este entorno ni se dirimen solamente a través de los organismos de derechos humanos. El juicio a los militares como a otros agentes participes de delitos de lesa humanidad se visibiliza por diversos medios y estrategias.

Estos son diversos y enumerarlos seria dejar de lado algunos de ellos. Sin embargo vale la pena destacar que los juicios son orales y públicos, a la par que difundidos por la prensa escrita, televisiva y radial; que ciertos órganos de la prensa escrita han instituido un espacio de homenaje anual para cada desaparecido en la fecha de su desaparición. ${ }^{13}$ Amen de las marchas anuales y otros tantos hechos evocativos: placas en los sitios donde vivió o desapareció una persona; la creación del Museo de la Memoria en la ex Escuela de Mecánica de la Armada (ESMA), que fuera uno de los tantos centros clandestinos de detención de la dictadura; una importante producción de documentales y films; la recuperación de la identidad de más de 100 nietos que habían sido apropiados por militares, policías o civiles afines a la dictadura, producto de la lucha de las Abuelas de Plaza de Mayo. Acciones encaminadas a preservar la memoria, desterrar la impunidad y lograr que se haga justicia.

Por último, recuperar la historia, como se ha intentado a través de estas narraciones, es un esfuerzo de relectura de los hechos que puede contribuir a disipar aquellas creencias que culpabilizan, inmovilizan, 


\section{ignoran, desinforman. Y en ello la escuela y la educación tienen una ta- rea importante: la recreación reflexiva de la memoria.}

\section{Notas}

1. Los cambios de denominación en general han obedecido a la hegemonía de ciertas perspectivas teóricas o bien al predominio y desplazamiento de una disciplina por otra.

2. El gobierno del Presidente Ricardo Alfonsín (1983-1989) primero decidió iniciar los Juicios a los militares responsables de delitos de lesa humanidad, acción promovida a su vez por los distintos organismos de derechos humanos: Madres y Abuelas de Plaza de Mayo, Familiares de Desaparecidos por razones políticos, Asociación de Ex Presos Políticos; el Centro de Estudios Legales y Sociales (CELS), la Asamblea Permanente por los Derechos Humanos; Hijos; SERPAJ y otras tantas organizaciones que nacieron durante la misma dictadura. Pero pese a estos logros la presión militar logró retrotraer a situaciones de nueva impunidad a los militares y a otros actores responsables de dichos delitos. Más tarde se continúo con el indulto del Presidente Menem.

3. Entre estas secuelas se destacan la desaparición de 30.000 personas, secuestro y cambio de identidad de niños nacidos en cautiverio, además de muertos.

4. En el período democrático han sucedido una serie de hechos, algunos de los cuales fueron causados por represiones policiales, por negligencias en los aparatos de control del Estado, o bien por actos de terrorismo. En la mayoría de estas situaciones se han producido muertes y otras consecuencias sobre la vida de personas. La contracara ha sido la conformación de grupos de protesta y gestión, constituidos por los familiares de las víctimas. Hay muchos y diversos ejemplos. Uno de ello es Cromañon - nombre derivado de un lugar de espectáculos musicales - en el cual murieron 200 jóvenes asfixiados. O bien el Grupo de la AMIA - mutual judía - que sufrió un atentado terrorista en 1988, en el que perdieron la vida cerca de 80 personas. También la muerte de una importante franja de militantes de movimientos sociales y/o de trabajadores. En todos los casos son conmemorados los aniversarios y se continúa con el pedido de justicia y esclarecimiento de los hechos. Existen asimismo otras agrupaciones como las Madres del Dolor, cuyos hijos fueron víctimas de la represión policial, o bien las Madres del Paco, víctimas de esta droga - sea por su consumo tanto como su implicación en las redes de distribución. Cabe aclarar que todos estos grupos cuentan con el apoyo de la población en general y de otras organizaciones sociales quienes adhieren a los actos de homenaje y reclamo de justicia.

5. Con la democracia se crean, en el sistema educativo de la ciudad y provincia de Buenos Aires, las Direcciones de Investigaciones Educativas que concretan proyectos de investigación y capacitación que promovían mayor participación y reflexión de los marcos autoritarios dentro de la escuela. También cabe mencionar el Congreso Pedagógico realizado en 1984-1985.

6. Además de la escuela analizada existían en el barrio otras tres escuelas públicas primarias, pero esta tenía un aspecto distintivo, su acceso era a través de una calle de tierra que se volvía intransitable en días de lluvia, a lo que se aunaba la precariedad edilicia, tornándola en un lugar menos deseable y por tanto menos escogido para estudiar y trabajar.

7. Chapa, lamina de lata, que no aísla del clima externo, por tanto muy caliente en el verano y muy frío en el invierno.

Cad. Cedes, Campinas, vol. 31, n. 83, p. 79-101, jan.-abr. 2011

Disponível em <http://www.cedes.unicamp.br> 
Escuela y barrio: memorias y narraciones de la democracia y la dictadura argentina

8. Estos baños no tienen vaso ni esgoto.

9 La deuda externa contraída durante la dictadura era más bien de carácter privado que estatal. Pero es en 1982 que el entonces Presidente del Banco Central Argentino - posteriormente ministro de Economía con Menen y De La Rua - Domingo Cavallo, estatiza tal deuda.

10. Para más información ver Dossier (2005) y Corbalan (2002).

11. Estos eran algunas de las cuestiones a observar: apariencia física, conducta motriz, estabilidad emocional, relaciones personales, rendimiento escolar.

12. Eran nueve los militares condenados, aquellos correspondientes a las tres juntas militares que tuvo esta dictadura.

13. El Diario al que nos referimos se llama Pagina 12, el cual en forma gratuita publica en sus páginas el recordatorio mencionado, acompañado de fotos y escritos varios.

\section{Referencias}

ARGENTINA. Ministerio de Educación, Ciencia y Tecnología. A cien años de la Ley Lainez. Buenos Aires: Ministerio de Educación, Ciencia y Tecnología, 2005.

AUGE, M. Ficciones de fin de siglo. Barcelona: GEDISA, 2001.

CORBALÁN, M.A. El Banco Mundial: intervención y disciplinamiento. Buenos Aires: Biblos, 2002.

DOSSIER. Espacios en blanco: revista de Educación, Tandil, n. 15, jun. 2005.

MAIORANA, M. La construcción de territorialidad y el conflicto irregular urbano. 2008. Dissertação. (Mestrado em Trabalho Social) - Facultad de Trabajo Social, Universidad Nacional de La Plata, La Plata.

MARTIGNONI, L. Obligatoriedad escolar y estrategias de retención en el tercer ciclo de la EGB: Provincia de Buenos Aires 1997-2001. 2002. Dissertação (Mestrado em Educação) - Universidade Estadual de Campinas, Campinas; Universidad Nacional del Centro de la Provincia de Buenos Aires, Buenos Aires.

MARTIGNONI, L. Experiencias adolescentes en el gobierno de la pobre$z a$. 2008. Tese (Doutorado em Ciencias Sociais) - Facultad Latinoamericana de Ciencias Sociales, Buenos Aires. 
SENNETT, R. La corrosión del carácter: las consecuencias personales del trabajo en el nuevo capitalismo. Barcelona: Anagrama, 2000.

Recebido em agosto de 2010.

Aprovado em outubro 2010. 